Original Research

\title{
Littering in Developing Countries: The Case of Jordan
}

\author{
Shadi Moqbel ${ }^{1 *}$, Ziad El-tah ${ }^{2}$, Assal Haddad ${ }^{3}$ \\ ${ }^{1}$ Civil Engineering Department, The University of Jordan, Amman, Jordan \\ ${ }^{2}$ Psychological Science and Special Education Department, Al-alBayt University, Mafraq, Jordan \\ ${ }^{3}$ Civil Engineering Department, American University of Madaba, Amman, Jordan
}

Received: 1 June 2018

Accepted: 3 September 2018

\begin{abstract}
Improving solid waste management practices and policies in developing countries requires handling of difficult topics such as littering. In this work we investigated littering in Jordan, a developing countries. A questionnaire was constructed to solicit people's justification for littering. The questionnaire considered three categories: social reasons, physical reasons, and psychological reasons. In addition, the study considered the socio-demographic characteristics of the respondents. People's view of the norm in Jordan, their education, and the belief that litter cleaning is not their job were the most significant reasons in the social category for littering. Infrastructure and honoring bread were the most significant reasons in the physical reasons for littering. Disgust and fear of sickness were the most significant reasons among the psychological reasons for littering. Results of the socio-demographical characteristics study indicate that young people and people aged 50 years and above tend to litter more, minimum education and basic environmental awareness are crucial in improving people's littering behavior, littering is not related to income, and there are no gender differences in littering for psychological reasons.
\end{abstract}

Keywords: littering, waste management, developing countries, Jordan

\section{Introduction}

Urban areas expansion and rapid increases in population have forced developing countries' governments and local municipalities to rethink the way their solid waste management programs are conducted. A challenging part of this management system is litter control. Litter is generally caused by unintentional fallen debris; wind-blown garbage from landfills, garbage trucks, and open waste containers; and people throwing

*e-mail: s.moqbel@ju.edu.jo their waste around (littering). Litter from fallen debris or wind-blown garbage can be related to the presence of waste in unsecured locations or overfilled storage areas, while people littering is directly related to their behavior in any location - indoors or outdoors. Littering is a pervasive problem that is aesthetically offensive [1]. It can threaten wildlife, block stormwater systems, threaten marine ecosystems, and affect investments and business development where littered places repel customers [2, 3]. With the population increase and people moving to every location they can reach, littering is becoming an expansive problem for solid waste management departments in municipalities. The consequences of increased littering include increasing 
capital and operational costs of cleaning programs by hiring more crews and sending street-cleaning trucks in two shifts or more for cleaning streets and parks.

Littering in Jordan, a developing country, is becoming a serious concern. Jordan is currently located in an area of turmoil. During the last two decades Jordan has hosted refugees from several countries: Iraq, Libya, Yemen, and Syria. As a result, the population in Jordan has nearly doubled over a period of 15 years (from 4,857,000 in 2000 to 9,559,000 in 2015). Currently, refugees make up about one third of the population in Jordan [4]. Accordingly, Jordan may be considered a microcosm of the people living in the Middle East. The unprecedented increase in population created a massive stress on resources and services provided by the government that created a threat to the quality of life. Streets and parks cleaning and litter removal were among the heavily affected services. Over the years, authorities and nongovernmental organizations have tried to adopt regulations and initiatives to control littering, imitating regulations and initiatives used in developed countries. These regulations and initiatives fell short after a short period because of the unsuitability of the measures used with the culture prevailing in the area, the lack of enforcement, and rejection and doubt of intentions exercised by people for programs used by developed countries and implemented in their country. Therefore, characterization of the social aspect of the litter problem that defines the relationship between people and their littering behavior was needed in order to form a base that may be used for generating regulations and initiatives from within the community.

A traditional step in the solid waste management process is waste reduction at the source. In litter control this means making people stop littering. Despite the fact that carrying waste material is inconvenient for most people [1], proper disposal of this waste is everyone's responsibility. For efficient waste reduction, it is imperative to understand the reasons of littering by individuals. A major factor in crafting an appropriate litter control system is understanding the reasons behind an individual's decision that leaving unwanted material around or throwing it is better than carrying it to a designated bin or receptacle. Such understanding will enable focused work toward tailoring solutions that are effective and more appropriate to the people's culture. Literature has been enriched over the years with the publication of litter control, mainly in developed countries. While literature had enormous work on littering, few studies have been found that have reported asking people directly about their reasons for littering. The organization Keep America Beautiful (KAB) has conducted frequent studies and produced periodic reports on littering in the USA [5]. In 2009 they issued a report presenting results of a nationwide survey study on littering behavior. In their survey, they asked people numerous questions about conditions that may accompany littering. They asked people which of the following reasons best explain why they litter: the item they are holding is not recyclable, they are in bad mood, they know someone else around will pick it up, they don't have time to take care of it, there is no nearby trash can or bag, or the item is biodegradable [5]. Hansmann and Steimer [6] conducted a questionnaire-based survey on 147 people from Swiss cities. The questionnaire solicited respondents' opinions on littering: Have they littered in the past? If so, why? Also, in their opinion, why do others litter? The questionnaire asked for openended answers, and the study concluded that one's own littering is often justified by external causes such as inadequate infrastructure or filled garbage cans, while littering by others is caused by ignorance, naivety, and convenience. Al-Khatib et al. [7] constructed a questionnaire and asked a sample of 1000 person from Nablus-Palestinian Territory to answer 5 groups of question about littering. One group of these questions included direct questions: If you litter, why? How often? What type of waste do you throw? When answering these questions, the respondents were asked to choose the main drive for littering, including: insufficient waste cans, habit, laziness, dirtiness of the street, lack of law enforcement, and for fun. The researchers concluded that the main reason for littering is insufficient waste receptacles, followed by the dirtiness of the street, and then laziness. The bulk of studies on litter in literature have focused on giving behavior predictors based on profiling criteria (e.g., gender, age, or education) or physical description of the place (e.g., littered place vs. clean place) or the waste material itself (e.g., fliers or cans) [1, 8-10]; factors affecting littering such as persuasive trash cans, environmental awareness, or penalties [11-14]; interaction between littering people and society [2, 15-17].

Cultural belief is a major factor in waste generation differences between nations [18]. While street cleaning is disliked in Singapore and millions of dollars are paid for waste removal, waste is valued in Japan and cleaning is honorable and considered productive, therefore little money is spent on waste removal [19]. In Australia, although extensive anti-littering campaigns have been continuously conducted, littering behavior has not changed in 50 years [20]. Madhani [20] commented that sources of littering increased over the years, where smoking bans shifted cigarette butts from ashtrays to outdoor environments and greening actives for parks and roofs resulted in more grass clippings, leaves and fine sediments in streets.

This work, investigates the reasons for littering in Jordan, which is not limited to specific places. Waste can be see clearly in open and closed areas, making it a surface-based pollution problem. Waste removal from streets and parks consumes a considerable percentage of municipalities' budgets and workforces. There have been no studies in literature reporting on littering behavior in Jordan, nor there have been any data in this regard. The purpose of this work is to bridge the gap and highlight the differences between developed countries' waste reduction activities as adopted by governments 
and actual people's behavior in a Middle Eastern country. The study is meant to give a better understanding of the littering problem in Jordan, gain a perspective on littering attitude and behavior, and provide recommendations that will help set guidelines for any proposed anti-littering campaigns. This study tries to answer the questions: Why do people in a country like Jordan litter? And are there any differences in littering behavior according to the socio-demographic factors? To achieve the purpose of this work a questionnaire was constructed and distributed to solicit opinions on littering. The questionnaire considered three categories for littering reasons: two categories that have been used previously in literature (social and physical), and a new category that has not been marked or considered directly before this work: psychological reasons. Responses to this questionnaire were analyzed and correlated to personal characteristics of the respondents (gender, education, age, environmental awareness, and income).

Based on a literature review and characteristics of the people in Jordan, the following hypotheses were tested:

1. All social reasons have a significant relationship with littering behavior.

2. All physical reasons have a significant relationship with littering behavior.

3. All psychological reasons have a significant relationship with littering behavior.

4. No significant differences in people's responses to social reasons, according to the characteristics of the respondent.

5. No significant differences in people's responses to the physical reasons, according to the characteristics of the respondent.

6. No significant differences in people's responses to the psychological reasons, according to the characteristics of the respondent.

\section{Material and Methods}

\section{Questionnaire Formulation}

A questionnaire-based survey was conducted to understand why people might litter in Jordan. The questionnaire focused on the case of being attentive and aware of the act of littering. The questionnaire did not consider the case of being distracted or if litter fell without a person's knowledge. Based on available literature and the culture of Jordan, reasons for littering were presented in the form of statements that the respondent has to choose between five answers: strongly disagree, disagree, neutral, agree, or strongly agree. Littering reasons considered in the questionnaire covered several topics: norms among people, education, peer pressure, sense of responsibility, feel of belonging to the area, available infrastructure, size of waste, moisture condition of the waste, organic content of the waste, physical properties of the garbage containers, the presence of stray cats and dogs, fear, disgust, laziness, the presence of litter in the area, packaging material significance, and the presence of bystanders. After reviewing literature, the researchers divided the reasons for littering into three dimensions: social, physical and physiological. Forty-two statements were written to measure littering reasons and potential causes, and these statements were scrutinized by specialists in social sciences and psychology in order to extract face validity through judging the adequacy of the statements to measure littering reasons and the linguistic formulation of these statements. Upon the notes given by the specialist, some statements were modified and two statements were deleted. Therefore, the initial edition of the questionnaire consisted of 40 statements. In order to conduct the statistical analysis, the respondents' answers to the questionnaire were given a numerical value (strongly disagree $=1$, disagree $=2$, neutral $=3$, agree $=4$, strongly agree $=5$ ). Then the scale was applied to a trial sample from outside the study sample. Results collected from this sample were analyzed and correlation coefficients between the score of each statement and the total score of the dimension and the total score of the scale were extracted. As a result, statements of negative correlations with the total score and statement with no statistical significance were deleted, which amounted to 10 statements that reduced the scale to 30 statements for the reasons divided on the dimensions as: 10 statements for social reasons (statements 1-10), 14 statements for physical reasons (statements 11-24), and 6 statements for psychological reasons (statements 25-30).

From the data collected from the trial sample, reliability of the scale was extracted in two ways: the internal consistency by extracting Cronbach alpha and test-retest procedure, where the scale was re-applied to the same outside sample after a period of 10 days. Cronbach alpha coefficient obtained for littering reason statements were: social reasons $\alpha=0.8$, physical reasons $\alpha=0.87$, and psychological reasons $\alpha=0.89$, and the entire scale $\alpha=0.93$. The test-retest procedure results were all significant at $p=0.001$. Following the results of the Cronbach alpha test and test-retest, the remaining statements were found to be statistically suitable to meet these study objectives.

\section{Questionnaire Distribution}

In outreaching to people and obtaining their opinions we used two approaches: online survey and face-to-face survey. In the online part, a web-based questionnaire was created and shared via social media. Also, a simple paid advertisement targeted Jordanians on Facebook. The advertisement asked people to volunteer to answer this questionnaire. In the face-toface survey, hard copies were printed and the locations of people from different parts and districts of Jordan were sought (mainly university campuses). In these 
areas, people were also asked to volunteer to answer this questionnaire.

\section{Results and Discussion}

Numerous reasons have been considered during the questionnaire formulation. Following the test-retest procedure and Cronbach alpha calculations, several reasons were removed due to statistical insignificance. Among these reasons were: pre-littered places, waste containers overfilled, plastic bag value, fear of stray cats and dogs standing next to waste containers, and feelings of shame for being seen standing next to a waste container.

The total of volunteer respondents who answered the questionnaire from the study sample were 576 persons (255 respondents from online survey and 321 respondents from face-to-face survey). During the analysis of the questionnaire results, two approaches were used: first, the scaling method, the score for each reason was calculated as the mean of answers. The single reason was considered statistically weak if it was less than 2.4, medium reason for a score of 2.4-3.6, and strong reason for a score higher than 3.6. For the entire dimension score, the number of reasons was considered in formulating the dimension's score. The score for social reasons can range from 10-50, and if it has a score less than 24 then it will be weak but if it has a score of 24-36 then it will be moderate and if it has the score 37 or above then it will be strong. For the physical reasons, the score can range from 14-70, if it has a score less than 33 it will be weak but if it has a score 33-51 it will be moderate and if it has a score 52 or above it will be considered strong. For the psychological reasons, the score can range from 6-30, if it has a score less than 16 it will be weak but if it has a score 16-25 it will be moderate and if it has a score 26 or above it will be strong. Second, for the littering possibility answers were divided into possibility-ranked categories due to the fact that having a piece of litter present in the street or in a public place does not indicate whether the person who threw it was a first-time litterer or a frequent litterer. A score of 1 or strongly disagree was considered as close to zero possibility for littering. Scores of 2 and 3 were considered low and medium possibilities, respectively. Results of 4 and 5 were combined into a high possibility of littering.

Questionnaire results for social reasons are presented in Table 1. Results for mean values of respondents' answers to social reasons show that most of the listed reasons are considered as weak for littering, except for the norm behavior in the society, where it is considered a medium-strength reason for littering. The results show some sort of contradiction. The overall answers indicate that people are against littering, but a high percentage of them consider the norm in Jordan to be accepting littering, which might be used as a justification to litter. Such an observation is consistent with Cialdini et al. [21], where a descriptive norm (which is done by people) might be different from the injunctive norm (which is morally approved). The questionnaire revealed that about $70 \%$ of the people reported that they might litter because they think the norm is to litter. This result should be alarming to decision-makers since this idea might result in shifting the general attitude toward littering from rejection to acceptance. Table 1 shows that the absence of anti-littering teachings and considering the cleaning of streets and public areas as other people's job has significant value. The importance of teaching anti-littering behavior to kids is well represented in Keenan [22] and Long et al. [23]. The result of relying on others to clean the streets and public areas shows consistency with KAB [5]. Percentages associated with these results indicate a crucial deficit in building the morals of a society. Teaching anti-littering behavior

Table 1. Respondent scores and littering possibilities for social reasons.

\begin{tabular}{|c|c|c|c|c|c|}
\hline \multirow{2}{*}{ Reason } & \multirow{2}{*}{ Score } & \multicolumn{4}{|c|}{ Littering possibility } \\
\cline { 3 - 6 } & & Low & Mid & High & Total \\
\hline Throwing litter in the waste containers is against the people norm here & 2.81 & 18.4 & 13.0 & 39.2 & 70.6 \\
\hline No one taught me to use the waste containers & 2.13 & 28.8 & 11.6 & 17.9 & 58.3 \\
\hline Presence of stranger bystanders affect my decision to litter & 1.53 & 23.1 & 6.3 & 5.0 & 34.4 \\
\hline Presence of known bystanders affect my decision to litter & 1.53 & 23.3 & 6.3 & 4.9 & 34.5 \\
\hline Presence of people monitoring affect my decision to litter & 1.50 & 22.7 & 4.9 & 5.2 & 32.8 \\
\hline My friends do it & 1.51 & 22.9 & 7.6 & 3.8 & 34.3 \\
\hline Cleaning streets and public areas is not my job & 2.29 & 25.2 & 24.5 & 16.5 & 66.2 \\
\hline I leave garbage behind me on purpose & 1.36 & 18.2 & 5.2 & 2.3 & 25.7 \\
\hline I don't belong to this area & 1.48 & 21.5 & 6.3 & 4.0 & 31.8 \\
\hline I'm not returning to the area & 1.44 & 25.2 & 4.2 & 3.0 & 32.4 \\
\hline Overall & 17.58 & - & - & - & 2 \\
\hline
\end{tabular}


Table 2. Respondent scores and littering possibilities for physical reasons.

\begin{tabular}{|c|c|c|c|c|c|}
\hline \multirow{2}{*}{ Reason } & \multirow{3}{*}{ Score } & \multicolumn{3}{|c|}{ Littering possibility } \\
\cline { 3 - 5 } & & Low & Mid & High & Total \\
\hline Garbage containers are not present & 2.26 & 23.1 & 17.7 & 20.0 & 60.8 \\
\hline Garbage containers are located away from me & 2.01 & 26.7 & 14.8 & 13.4 & 54.9 \\
\hline Small size garbage does not harm the environment & 1.80 & 26.7 & 10.4 & 9.9 & 47 \\
\hline Moist or wet garbage does harm the environment & 1.72 & 31.1 & 8.5 & 7.5 & 47.1 \\
\hline Pouring drinks and liquid waste on the ground does not affect the environment & 1.89 & 28.6 & 13.7 & 9.7 & 52 \\
\hline Dry garbage does not harm the environment & 1.63 & 30.6 & 8.5 & 4.7 & 43.8 \\
\hline Cigarette butts does not harm the environment & 1.70 & 26.4 & 9.2 & 7.8 & 43.4 \\
\hline Plastic packaging wrap does not affect the environment & 1.47 & 25.3 & 5.0 & 3.3 & 33.6 \\
\hline I don't like the garbage containers smell & 1.82 & 25.9 & 11.1 & 10.1 & 47.1 \\
\hline Garbage container opening is high & 1.70 & 29.9 & 10.2 & 5.9 & 46 \\
\hline Garbage container design is not practical & 1.75 & 28.1 & 11.6 & 6.9 & 46.6 \\
\hline I don't like the garbage container color & 1.60 & 23.8 & 8.0 & 6.1 & 37.9 \\
\hline Food waste will decompose & 1.81 & 26.2 & 11.5 & 9.5 & 47.2 \\
\hline I don't put bread and food leftover in the garbage container & 2.67 & 18.6 & 21.0 & 31.6 & 71.2 \\
\hline Overall & 25.83 & - & - & - & \\
\hline
\end{tabular}

and the importance of cleaning the area where people live without relying on others should be incorporated within the curriculum of the primary level of education. Table 1 indicates that the bystander effect is nearly the same, regardless of being a stranger or known person. Moreover, cleaning monitoring persons had a very small impact on reducing littering behavior. Being with friends, not belonging to the area, and not returning to the area scores were among the lowest. Long et al. [23] reported that a friend's prior behavior toward littering can be predictive of one's own behavior. Respondent answers weakly agree with Long et al. [23], which can be related to cultural differences where a person in a Middle Eastern culture strives to show uniqueness in behavior no matter how simple the action. Although not belonging to an area and not returning scores were low, they indicate a justification that some people might use for littering. No comparison could be made with literature in this regard. Generally, littering possibility estimation shows a similar pattern to the scoring system. However, forecasting the total number of people who might litter whether it is a high possibility or a low possibility using total potential for people littering possibility gives a significantly high number.

Questionnaire results for physical reasons are presented in Table 2. Mean values of respondents' answers to physical reasons show that most of the listed reasons are considered weak for littering, except for leaving bread next to the garbage container, where it is considered a medium-strength reason. Bread is generally honored in Middle Eastern countries, therefore leftover dry bread or spoiled bread is usually disposed of separately from municipal household waste. When separated from the waste, leftover bread is usually put aside for stray animals or wandering shepherd's to feed their cattle. No comparison could be made in literature regarding leftover bread in Middle Eastern countries. The presence of containers, distances to containers, and pouring drinks and liquid waste on the ground were noticeably higher than other reasons. The presence of receptacles and distances to receptacles results were consistent with results mentioned in Finnie [24]. Liquid waste pouring on the ground appears to be relatively more accepted, which could be related to the belief that its content will evaporate and what is left will decompose over time. The littering cigarette butts result shows some acceptance among people, which is consistent with Al-Khatib et al. [7] and Madhani et al. [20]. The physical appearance of a waste container plays a significant role in littering behavior. Results that justify littering according to the physical appearance and appropriate design of waste containers can be considered noteworthy. Such a note is partially consistent with de Kort et al. [11], who presented the idea of persuasive trash receptacles as being an influential approach for litter control. Littering possibility estimation shows a generally similar pattern. Among high possibility reasons, the presence of waste containers and leaving bread next to waste containers were remarkably higher than medium possibility, which might indicate wider acceptance. Interestingly, throwing waste because it is wet, dry waste does not harm the environment, and the height of container opening were remarkably higher among low-possibility littering. 
Table 3. Respondent scores and littering possibilities for psychological reasons.

\begin{tabular}{|c|c|c|c|c|c|}
\hline Reasons & \multirow{3}{*}{ Score } & \multicolumn{3}{|c|}{ Littering possibility } \\
\cline { 3 - 6 } & & Low & Mid & High & Total \\
\hline Laziness & 1.60 & 25.3 & 8.5 & 5.0 & 38.8 \\
\hline I'm afraid of germs & 1.62 & 27.1 & 6.9 & 6.4 & 40.4 \\
\hline Out of disgust & 1.77 & 25.2 & 11.5 & 8.7 & 45.4 \\
\hline I will take a shower if I used the garbage container & 1.59 & 27.8 & 7.6 & 4.7 & 40.1 \\
\hline I will get sick if I used the garbage container & 1.75 & 27.1 & 11.3 & 7.6 & 46 \\
\hline I'm afraid of others criticism when using the garbage container & 1.61 & 22.2 & 7.6 & 6.6 & 36.4 \\
\hline Overall & 9.94 & - & - & - & \\
\hline
\end{tabular}

Questionnaire results for psychological reasons are presented in Table 3. The mean value of respondents' answers to psychological reasons show that most of the listed reasons for littering are considered weak. Within these reasons, feelings of disgust and fear of sickness when approaching waste containers were noticeably higher than other reasons. Unfortunately, no publication has been found to report these two causes. On the other hand, laziness has been reported in Al-Khatib et al. [7] and Schultz et al. [9], but it does not seem to be stronger than the feeling of disgust and fear of sickness. Littering possibility estimation for psychological reasons shows a similar pattern but is generally less than physical and social reasons.

Considering overall results for each category, we can see that physical reasons have a stronger influence on littering behavior, followed by social and then psychological reasons. Results show that the general attitude among respondents is against littering. However, skewness in the results and the distribution of respondent answers according to the possibility of littering illustrate a relatively very small percentage of people who are frequent litterers. Remarkably, the percentage of people who litter less frequently are higher to a great extent. Taking into account this percentage and the possibility of littering, the total amount of litter from less frequent litterers can be comparable or higher than frequent litterers.
The questionnaire responses were statistically analyzed using SPSS statistical software according to the respondent's personal characteristics. Gender behavior differences have been reported in literature in regards to littering. Therefore, it was primitive to investigate littering behavior according to gender. The male and female percentages in the study sample were $48.26 \%$ males and $51.74 \%$ females. The male scores in the questionnaire were as follows: social reasons (1.844 \pm 0.669$)$, physical reasons $(1.929 \pm 0.755)$, and psychological reasons $(1.721 \pm 0.821)$. Female scores were: social reasons $(1.678 \pm 0.579)$, physical reasons (1.767 \pm 0.69$)$, and psychological reasons (1.598 \pm 0.727$)$. Results of mean value according to gender reveal that mean values for males are slightly higher than for females, which indicates that males in general may throw litter more than females. The significance of these figures was investigated using independent t-test at $\alpha=0.05$ for comparing means between male and female responses. T-test results for each of the dimensions specified in the questionnaire revealed that males are susceptible to social pressure $(\mathrm{t}=3.197, \mathrm{p}=0.001)$ and physical reasons $(\mathrm{t}=2.687, \mathrm{p}=0.007)$ more than females, while for psychological reasons $(t=1.897, p=0.058)$ no significant differences were concluded. Literature reports of differences between male and female littering shows two opposite results: males are more likely to litter than females $[7,12]$ and there is no gender effect

Table 4. Respondent scores and ANOVA test results according to educational level.

\begin{tabular}{|c|c|c|c|c|c|c|c|}
\hline & & \multicolumn{2}{|c|}{ Social reasons } & \multicolumn{2}{c|}{ Physical reasons } & \multicolumn{2}{c|}{ Psychological reasons } \\
\hline Education & $\mathrm{N} \%$ & Mean & Std. Dev. & Mean & Std. Dev. & Mean & Std. Dev. \\
\hline Primary & 5.56 & 2.003 & 0.614 & 2.236 & 0.867 & 2.026 & 0.976 \\
\hline Secondary & 29.69 & 1.903 & 0.669 & 2.018 & 0.754 & 1.814 & 0.785 \\
\hline Bachelor & 53.47 & 1.711 & 0.619 & 1.793 & 0.684 & 1.585 & 0.727 \\
\hline Higher education & 11.28 & 1.482 & 0.419 & 1.445 & 0.536 & 1.408 & 0.723 \\
\hline F test & & 9.843 & & 14.388 & & 8.193 & \\
\hline Significance & & 0.000 & & 0.000 & & 0.000 & \\
\hline
\end{tabular}


Table 5. Respondents scores and ANOVA test results according to age.

\begin{tabular}{|c|c|c|c|c|c|c|c|}
\hline & & \multicolumn{2}{|c|}{ Social reasons } & \multicolumn{2}{|c|}{ Physical reasons } & \multicolumn{2}{|c|}{ Psychological reasons } \\
\hline Age & $\mathrm{N} \%$ & Mean & Std. Div. & Mean & Std. Div. & Mean & Std. Div. \\
\hline Under 20 & 13.54 & 1.872 & 0.555 & 2.077 & 0.693 & 1.854 & 0.744 \\
\hline $20-30$ & 42.19 & 1.916 & 0.726 & 1.955 & 0.781 & 1.79 & 0.851 \\
\hline $30-40$ & 21.35 & 1.577 & 0.472 & 1.678 & 0.608 & 1.44 & 0.596 \\
\hline $40-50$ & 15.28 & 1.543 & 0.496 & 1.662 & 0.675 & 1.46 & 0.668 \\
\hline Above 50 & 7.64 & 1.623 & 0.078 & 1.657 & 0.665 & 1.575 & 0.802 \\
\hline F test & & 10.748 & & 7.454 & & 7.324 & \\
\hline Significance & & 0.000 & & 0.000 & & 0.000 & \\
\hline
\end{tabular}

on littering $[9,24]$. Results of this study may clear some of these differences in literature reporting.

Results of respondent answers according to education level are listed in Table 4. Comparing the effects of educational level on littering behavior was delineated using one-way ANOVA test at $\alpha=0.05$. Results of the ANOVA test are presented in Table 4. Results from the ANOVA test showed statistically significant differences among educational levels of respondents, therefore Scheffe's post hoc test was performed to determine the main difference. Scheffe and ANOVA tests revealed that as educational level increases, littering behavior improves and the possibility of littering is reduced. Specifically, results suggest that people with a university degree have better littering behavior. Results of the effect of educational level show consistency with Arafat et al. [25], and partially contradicts Ajaegbo et al. [8]. Ajaegbo et al. [8] reported that no relationship could be obtained between education and littering attitude; however, they reported a distinct difference between highly educated people and people with lower education, which was consistent with the results of this study.

Results of respondent answers according to age are listed in Table 5. The significance of these figures were investigated using one-way ANOVA at $\alpha=0.05$. ANOVA results showed statistical significance difference among age categories on littering behavior, therefore the Scheffe post hoc test was performed. Results of Scheffe for the effect of age indicated that littering becomes less as a person ages. Nevertheless, for social and psychological reasons this idea does not hold for people aged 50 and above. Littering is higher at ages under 20 than between 20 and 30 years. People aged 30-40 and 40-50 years litter the least. Results of people littering when they progress with age up to 50 years, as presented in this study, are consistent with Schultz et al. [9] and Ojedokun [26]. After 50 years, people apparently become more susceptible to social and psychological pressure and their littering behavior deteriorates. For physical reasons, results show that littering behavior continues to decrease with progressing age.

Investigating the effect of knowledge and being familiar with environmental issues was conducted on three levels: no knowledge, basic knowledge and an expert knowledge. Results of the respondents' classifications and scores are presented in Table 6. The significance of these numbers were tested using one-way ANOVA at $\alpha=0.05$. Results from ANOVA showed the statistical significance effect of knowledge and awareness with environmental issues on littering behavior for the three dimensions at $p=0.000$. Therefore, Scheffe's post hoc test was performed. Results for the Scheffe post hoc test revealed that littering decreases as a person becomes more aware of and familiar with environmental issues and problems. No significant difference could be found between basic knowledge and being an expert, but the major difference is between no knowledge on one side and having basic knowledge and being an expert on the

Table 6. Respondent scores and ANOVA test results according to knowledge in environmental issues.

\begin{tabular}{|c|c|c|c|c|c|c|c|}
\hline \multicolumn{2}{|c|}{} & \multicolumn{2}{c|}{ Social reasons } & \multicolumn{2}{c|}{ Physical reasons } & \multicolumn{2}{c|}{ Psychological reasons } \\
\hline Environmental Knowledge & $\mathrm{N} \%$ & Mean & Std. Div. & Mean & Std. Div. & Mean & Std. Div. \\
\hline No & 16.32 & 2.115 & 0.767 & 2.298 & 0.947 & 2.069 & 0.961 \\
\hline Basic & 78.3 & 1.694 & 0.574 & 1.772 & 0.642 & 1.596 & 0.712 \\
\hline Expert & 5.38 & 1.61 & 0.569 & 1.525 & 0.568 & 1.29 & 0.535 \\
\hline F test & & 19.5 & & 25.546 & & 19.311 & \\
\hline Significance & & 0.000 & & 0.000 & & 0.000 & \\
\hline
\end{tabular}


other side, which indicates that basic knowledge could be enough to surprisingly enhance the littering behavior of people. Results of environmental awareness impact on littering was mainly reported for kids [23, 27]. The results of this study support Long et al. [23] and Hartley et al. [27], but only for adults.

Investigating the effect of monthly income on littering was conducted by dividing monthly income into four categories: less than $300 \mathrm{JD}, 300-500 \mathrm{JD}$, $500-1000 \mathrm{JD}$, and more than $1000 \mathrm{JD}$. Percentages of respondents in each of these categories were: $23.26 \%$, $32.81 \%, 24.83 \%$ and $19.1 \%$, respectively. Statistical analysis of the data associated with these monthly income categories did not reveal any significant difference among them. This contradicts the idea that increases in income are associated with litter reduction, as per Santos et al. [28].

Although this study has provided a wider perspective on what is known and presented in literature, it is worth acknowledging some of the limitations in this study. First, the sample size used in this study, 576 respondents, does not represent every individual residing in Jordan. Second, although the reported results were based on anonymous volunteering individuals, the type of social media and sites selected for collecting people's opinion was not random. These methods for approaching people were not representative of all people in Jordan. Third, the data presented in this study were based on self-reporting, which implicates potential bias by people to show good morals and behavior. Thus littering reporting is probably an underestimate of actual littering behavior. Fourth, reasons listed in the questionnaire were based on literature and the widely shown reasons in Middle Eastern culture, therefore this questionnaire did not include all possible reasons for littering behavior.

The overall view of the data obtained from littering reasons questionnaire and possibilities and the analysis based on respondent characteristics does not give a clear quick solution to the littering problem, but rather provides basic information for waste management decision makers on littering problems in developing countries and communities to Jordan. Reasons presented in this study are considered statistically weak reasons for littering, but ranking these provided reasons based on their scores gives a good indication of what could be used to reduce littering. Calculating the entire possibility of littering for these reasons can be significant and gives a very serious indicator of people's littering. A good strategy for preventing littering behavior could be tackling the highest influencing factors among each dimension of the reasons presented in this work on a nationwide plan. People's views of the norm where they live and education were significantly high among all reasons. A major factor that most likely plays a role in littering prevention and changing the norm is knowledge and awareness. It is recommended that decision-makers include anti-littering behavior as part of the educational system. Including litter control and education within the educational system and running environmental awareness campaigns are expected to improve littering behavior significantly among people and future generations. Investing in waste receptacle design and availability may eliminate many physical and psychological reasons for littering. Waste receptacles design and service should include making the receptacles appealing, user-friendly for elderly people, safe and more hygienic in appearance.

\section{Conclusions}

This study investigated the reasons for littering behavior in Jordan. The list of reasons was divided into three parts: social, physical, and psychological. Results of the questionnaire that investigated these reasons show that there is no statistically strong reason for littering. People vary in their behavior and therefore littering reasons vary. People's view of the norm in Jordan, education, and the idea that cleaning litter is not their job were the most significant reasons in the social category. Infrastructure and honoring bread not to be disposed of in waste receptacles were the most significant reasons in the physical category. And disgust and fear of sickness were the most significant reasons in the psychological category.

A socio-demographic study indicated that males are susceptible to social and physical reasons to litter more than females, while they are similar in front of psychological reasons. Results showed that young people and people aged 50 years and above tend to litter more, littering is not related to income, and education and environmental awareness can reduce littering behavior significantly.

\section{Conflict of Interest}

The authors declare no conflict of interest.

\section{References}

1. CLARK R., HENDEE J., BURGESS R. The experimental control of littering. The Journal of Environmental Education, 4 (2), 22, 1972.

2. OJEDOKUN O. Attitude towards littering as a mediator of the relationship between personality attributes and responsible environmental behavior. Waste Management, 31, 2601, 2011.

3. GOLUMBEANU M., NENCIU M. GALATCHI M., NITA V., ANTON E., OROS A., IOAKEIMIDIS C., BELCHIOR C. Marine litter watch app as a tool for ecological education and awareness raising along the Romanian black sea coast. J. of Environmental Protection and Ecology, 18 (1), 348, 2017.

4. Department of Statistics (DoS). Population census. Statistics Yearbook, 66, 2015.

5. Keep America Beautiful, "Littering behavior in America: Results of a national study", available online on: https:// 
www.kab.org/resources/end-littering (Last accessed on June $1^{\text {st }}$, 2018)

6. HANSMANN R., STEIMER N. Subjective reasons for littering: a self-serving attribution bias as justification process in an environmental behaviour model. Environmental Research, Engineering and Management, 73 (1), 8, 2017

7. AL-KHATIB I., ARAFAT H., DAOUD R., SHWAHNEH H. Enhanced solid waste management by understanding the effect of gender, income, marital status, and religious convictions on attitudes and practices related to street littering in Nablus-Palestinian territory. Waste Management, 29, 449, 2009.

8. AJAEGBO E., DASHIT S., AKUME A. The determinants of littering attitude in urban neighborhoods of Jos. J. of Research in National Development, 10 (3), 82, 2012.

9. SCHULTZ P., BATOR R., LARGE L., BRUNI C., TOBANICO J. Littering in context: personal and environmental predictors of littering behavior. Environment and Behavior, 45 (1), 35, 2013.

10. ASMUI M., ZAKI S., WAHID S., MOKHTAR N., HARITH S. Association between litterers' profile and littering behavior: a Chi-square approach. The $3^{\text {rd }}$ ISM International statistical conference, AIP conf. proc. 1842 (1), 2016.

11. DE KORT Y., MCCALLEY L., MIDDEN C. Persuasive trash cans. Environment and Behavior, 40 (6), 870, 2008.

12. TORGLER B., GARCIA-VALINAS M., MACINTYRE A.. Justifiability of littering: An empirical investigation. Environmental Values, 21 (2), 209, 2012.

13. BATESON M., CALLOW L., HOLMES J., REDMOND R., NETTLE D. Do images of "watching eyes" induce behaviour that is more pro-social or more normative? A field experiment on littering. PLoS ONE, 8 (2), 1, 2013.

14. KHAWAJA F., SHAH A. Determinants of littering: an experimental analysis. The Pakistan Development review, 52 (2), 157, 2013.

15. CHEKROUN P., BRAUER M. The bystander effect and social control behavior: the effect of the presence of others on people's reaction to norm violation. European Journal of Social Psychology, 32, 853, 2002.

16. PATEL V., THOMSON G., WILSON N. Cigarette butt littering in city streets: a new methodology for studying and results. Tobacco Control, 22, 59, 2013.
17. MACIAS A., PINIARSKI W. Municipal solid waste management problems on a local scale: A case study from rural Poland. Polish Journal of Environmental Studies, 25 (4), 1623,2016

18. WORRELL W., VESILIND P. Solid Waste Engineering. Thomson-Engineering $2^{\text {nd }}$ edition, USA, 2011.

19. ONG I., SOVACOOL B. A comparative study of littering and waste in Singapore and Japan. Resources, Conservation, and Recycling, 61, 35, 2012.

20. MADHANI J., DAWES L., BROWN R. A perspective on littering attitudes in Australia. The Environmental Engineer, 13, 2009.

21. CIALDINI R., RENO R., KALLGREEN C. A focus theory of normative conduct: recycling the concept of norms to reduce littering in public places. J. of Personality and Social Psychology, 58 (6), 1015, 1990.

22. KEENAN M. The A, B, C of litter control. The Irish Journal of Psychology, 17 (4), 327, 1996.

23. LONG J., HARRE N., ATKINSON Q. Understanding change in recycling and littering behavior across a school social network. American Journal of Community Psychology, 53, 462, 2014.

24. FINNIE W. Field experiments in litter control. Environment and Behavior, 5, 123, 1973.

25. ARAFAT H., ALKHATIB I., DAOUD R., SHWAHNEH $\mathrm{H}$. Influence of socio-economic factors on street litter generation in the Middle East: effects of education level, age, and type of residence. Waste Manage Research. 25, $363,2007$.

26. OJEDOKUN O. The Role of Socio-demographical and Psychological Factors in Taking Littering Prevention Actions. International Journal of Advances in Psychology (IJAP), 2 (4), 197, 2013.

27. HARTLEY B., THOMPSON R., PAHL S. Marine litter education boosts children's understanding and selfreported actions. Marine Pollution Bulletin, 90, 209, 2015.

28. SANTOS I., FRIEDRICH A., WALLER-KERSANACH M., FILLMANN G. Influence of socio-economic characteristics of beach users on litter generation. Ocean and Coastal Management, volume 48, 742, 2005. 